Johannesburg

bb.aisha@gmail.com

Cite this as: $B M J 2021 ; 374:$ :1949

http://dx.doi.org/10.1136/bmj.n1949

Published: 23 August 2021
COVID-19

\section{How South Africa is dragging its vaccine rollout back from the brink}

\section{South Africa planned early for its covid vaccination programme. Yet ongoing procurement problems and new variant fuelled waves have left its population vulnerable, reports Bibi-Aisha Wadvalla}

\section{Bibi-Aisha Wadvalla freelance journalist}

It's a winter of discontent in South Africa. Only a small fraction of the population is fully vaccinated as the country grapples with a third wave dominated by the Delta variant of covid-19. This forced the country into a one month "level 4 " lockdown (ended 25 July) that included a ban on all gatherings and alcohol sales, limitations on inter-provincial travel, and restaurant services limited to takeaways.

The number of hospitalisations is higher than the previous two waves, and more deaths are being reported. Nationwide there's an average of 13000 new daily cases, primarily driven by Gauteng province, the country's economic hub encompassing Johannesburg and Pretoria. In early July, hospitals in Gauteng ran out of beds, and private patients in intensive care units were airlifted to other provinces.

The rapid rise in cases is in stark contrast to the sluggish pace of South Africa's vaccination rollout, which has been plagued by numerous setbacks. In June, Mosa Moshabela, acting deputy vice-chancellor of research and innovation, University of KwaZulu-Natal, called the delays "unsatisfactory as they indicate a lack of urgency.”

Yet things were so different at the turn of the year.

In January, the Department of Health announced it had secured 12 million doses of vaccine from the global Covax facility, on top of the purchase of 1.5 million doses of the AstraZeneca vaccine earlier the same month. This made South Africa one of the few African countries with the supplies to conduct an extensive rollout.

But the vaccines have been slow to arrive. The much awaited Covax delivery due in March arrived only in the last week of June and contained just 1.4 million doses. And just as the AstraZeneca vaccine was about to be rolled out to healthcare workers in mid-February, concerns emerged that the vaccine may not be efficacious against the emerging Beta (B.1.351) variant identified in the country. ${ }^{1}$

\section{Setbacks}

The government took the drastic decision to pause the entire rollout of AstraZeneca vaccines. Within 10 days, Johnson \& Johnson's (J\&J's) vaccine, which was not part of the government's initial rollout plan, took its place, notionally under the expansion of an open label study already taking place in the country. Glenda Gray, president of the South African Medical Research Council, who had raised concerns about the AstraZeneca vaccine's lack of efficacy, leveraged contacts with J\&J-with whom the council already million replacement doses.

In mid-April, by which point close to 300 ooo jabs had been administered (enough to give one dose to $0.5 \%$ of South Africa's population of 60 million), reports of rare blood clots-an issue which has also plagued the AstraZeneca vaccine-emerged for the J\&J vaccine. South Africa followed other countries' precautionary measures and paused the J\&J vaccinations for two weeks.

This left the government agonisingly short of its targets. It had aimed to vaccinate 500 ooo health workers by the end of April, and 1.2 million by the end of May. By 17 May, 479768 were vaccinated out of a workforce of around 650000.

The rollout eventually resumed, but it hit another major setback in early June, when two million vials of the J\&J vaccine had to be thrown away after a high profile contamination at source in the United States.

Then the riots in mid-July, sparked by the imprisonment of former president Jacob Zuma, ended with nearly 100 vaccination sites, public and private, being damaged, and 47000 doses stolen.

This rollercoaster ride has given AstraZeneca a second chance. According to Moshabela, the government is willing to reconsider the Oxford-AstraZeneca vaccine with new studies showing it does prevent severe disease and death from the Beta and Delta variants, ${ }^{2}$ the two variants currently responsible for most cases in South Africa. Barry Schoub, chair of the Ministerial Advisory Committee on Covid Vaccines, says that despite what happened in February, the vaccine was never fully dismissed.

Moshabela is critical of the decision to suspend the use of the AstraZeneca vaccine in January, which was based on "limited evidence," he says. "The ramifications of that decision were much greater," he told The BMJ, referencing the subsequent troubles with the vaccine rollout generally.

With new vaccine candidates entering the global market, there are calls for these to be considered as well. Schoub says that the Ministerial Advisory Committee on Covid Vaccines has met with Novovax, but the pharmaceutical company has not yet submitted an application to the South African Health Products Regulatory Authority. The authority has conditionally approved the CoronaVac vaccine from China, but the Department of Health does not have an agreement in place with the Chinese manufacturer, Sinovac. partnered on HIV vaccine development-to get one 
It remains to be seen how any of the vaccines being discussed fare in the field. The emergence of Beta and Delta variants has lowered expectations of all vaccines, says Gray, who expects to see "breakthrough infections" but hopes they'll be mild.

\section{Uncertainty}

Unsurprisingly, most South Africans were uncertain as to when they'd be vaccinated. By late June, less than $1 \%$ (700 ooo) of the population was fully vaccinated. Among vaccinated health workers, 64 infections have been reported, mostly in those with severe comorbidities.

To put that in context, since 10 June, when the third wave is officially considered to have begun, South Africa has seen close to 700000 infections, 70 ooo hospital admissions, and 16 ooo deaths. Although some provinces seem to be over the peak, hospitals are still struggling. South African Medical Association chair, Angelique Coetzee, told The BMJ that with 16441 patients in the intensive care unit, and 1440 on ventilators, "doctors and nursing staff are overworked, overwhelmed and irritable as patients are extremely demanding, which doesn't help the situation." Although on a positive note, she says there are sufficient oxygen supplies, despite disruptions caused by the riots.

The government has purchased an additional nine million vaccine doses from J\&J, due in the second half of 2021, with local manufacturer Aspen taking care of "fill and finish" bottling. An additional 20 million doses from Pfizer are also due to arrive in the second half of 2021. A delivery of 10 million J\&J doses and about 16 million Pfizer doses are expected this quarter. But both delivery schedules have a degree of uncertainty given the supply issues affecting the world.

Nicholas Crisp, the Department of Health's deputy director general, who leads the vaccine rollout, told a media briefing on 23 June that there was no getting round the lack of available doses. "Both the private and public sector are champing at the bit to open up more sites [for vaccination]," he said. "In the short term we will have more volume, and vaccinations are expected to triple in the second half of the year to 300 ooo doses a day."

It took two months to administer two million doses to the $60+$ year old population, owing to delays in receiving supplies. Staff shortages and budgetary squeezes have also contributed to a low number of vaccination sites, especially in rural areas. Initially, the registration process was online only, which excluded millions who do not have access to the internet, but the government has acted swiftly to solve the problem. Walk-in centres have since been implemented, and community health workers have been deployed to assist the elderly, alongside hotlines to help with registrations.

At the time of writing, close to 250 ooo vaccines are being administered daily. Around 3.6 million people (8.5\%) are now fully vaccinated, while a further 6.8 million have received their first dose.

Issues remain, however. The decision to prioritise vaccination based purely on age, and not on high risk comorbidities such as diabetes, hypertension, and cardiac disease, has been criticised by Moshabela and others. Schoub told The BMJ, "We are still wanting to add the relatively smaller number of younger individuals with significant comorbidities to the high priority group, but will need to establish a workable and reliable verification system."

A national survey of 5862 people reported that $71 \%$ of South Africans were willing to be vaccinated, ${ }^{3}$ and figures from the country's electronic vaccine data system indicate that just over half in the 35-49 and 50-59 age groups have registered. But another survey found that of 1600 respondents, $52 \%$ said they're unlikely to choose to be vaccinated. ${ }^{4}$ Among vaccine hesitant people, frequently cited concerns are safety, the rushed development, and lack of testing.

The government has set a target to vaccinate $67 \%$ of the population by February 2022. Is that feasible? Harsha Somaroo, a public health medicine specialist at Wits University, answers a tentative, "yes.” By her calculations, 270776 people would need to be vaccinated for 30 days a month between August and February 2022. "It is theoretically achievable but will be very dependent on the contextual supply and demand factors," she told The BMJ. Consistency is key-something that has been in short supply so far.

\section{South Africa: a new hub for African vaccine manufacturing}

With vaccination rates on the rest of the continent remaining dismally low, the World Health Organization has chosen South Africa as a hub for the manufacture of vaccines. Aspen will from October manufacture vaccines solely for Africa, while the Biovac Institute in Cape Town was appointed to manufacture the Pfizer-BioNTech covid-19 vaccine for distribution within Africa.

Lara Dovifat, of Doctors Without Borders (MSF), called it a "first step, but not enough to achieve vaccine independence" in Africa. "The agreement fails to share Pfizer-BioNTech's (mRNA) technology to independently manufacture vaccines, and instead requires Biovac to remain dependent on drug substances from Pfizer-BioNTech's European facilities," she said in a statement.

Pfizer has also been criticised for a contractual demand that the South African government put up sovereign assets guaranteeing indemnity against the cost of any future legal cases over the vaccine. ${ }^{5}$

Competing interests: I have read and understood the BMJ policy on declaration of interests and have no relevant interests to declare.

Provenance and peer review: Commissioned; not externally peer reviewed.

Mahase E. Covid-19: South Africa pauses use of Oxford vaccine after study casts doubt on efficacy against variant. BMJ 2021;372:n372. doi: 10.1136/bmj.n372 pmid: 33558207

2 AstraZeneca. Vaxzevria is highly effective after one dose against severe disease or hospitalisation caused by Beta and Delta variants of concern. Jul 2021. https://www.astrazeneca.com/mediacentre/press- releases/2021/vaxzevria-is-highly-effective-after-one-dose-against-severe-diseaseor-hospitalisation-caused-by-beta-and-delta-variants-of-concern.html.

3 Burger R, Maughan-Brown B, Köhler T, English R, Tameris M. A shot in the arm for South Africa-increased openness to accepting a COVID-1789 vaccine: Evidence from NIDS-CRAM Waves 4 and 5. National Income Dynamics Study (NIDS)-Coronavirus Rapid Mobile Survey (CRAM). 8 Jul 2021. https://cramsurvey.org/wp-content/uploads/2021/07/2.-Burger-R.-MaughanBrown-M.-Kohler-T.-English-R.-_-Tameris-M.-2021-Increased-openness-to-accepting-a-COVID19-vaccine-is-a-shot-in-the-arm-for-South-Africa-Evidence-from-the-NIDS-CRAM-Wave-5-Survey.pdf.

4 AfroBarometer. South Africans unsure of safety of COVID-19 vaccines; many unlikely to get vaccinated. https://afrobarometer.org/press/south-africans-unsure-safety-covid-19-vaccines many-unlikely-get-vaccinated.

Davies M, Furneaux R. Pfizer backs down over "unreasonable" terms in South Africa vaccine deal. Mail \& Guardian2021 Apr 19. https://mg.co.za/news/2021-04-19-pfizer-backs-down-overunreasonable-terms-in-south-africa-vaccine-deal.

This article is made freely available for use in accordance with BMJ's website terms and conditions for the duration of the covid-19 pandemic or until otherwise determined by BMJ. You may use, download and print the article for any lawful, non-commercial purpose (including text and data mining) provided that all copyright notices and trade marks are retained. 